Volume 2 Issue 2, September 2018: pp. 545-555. Copyright (c) 2018 HOLREV. Faculty of Law, Halu Oleo University, Kendari, Southeast Sulawesi, Indonesia. ISSN: 2548-1762 | e-ISSN: 2548-1754. Open Access at: http://ojs.uho.ac.id/index.php/holrev/

Halu Oleo Law Review is licensed under a Creative Commons Attribution 4.0 International License, which permits unrestricted use, distribution, and reproduction in any medium, provided the original work is properly cited.

\title{
Tanggung Jawab Pengangkut dan Pengawas Pelayaran Pada Pelayaran Rakyat
}

\author{
Responsibility for Transporter and Supervisor of Sailorship on Citizen Sailing
}

\author{
Jabalnur \\ Fakultas Hukum Universitas Halu Oleo \\ E-mail: jabalnur821@gmail.com
}

\begin{abstract}
Nationally, sea transportation has a caracteristic and reached a broad range toward national territory need to be developed potential and enhanced role as liaisons among the regions, because it is used as a tool in order to support, encourage, and mobilize national development that has effort to increase social welfare. However, today, the transportation authority has not been maximal in implementing such to control ship's sea worthiness. The basic principle of sailing safety must be in sea worthiness condition. This meant, the ships must be able to deal with a variety of ways including waves and hurricanes.

The shipping organizers in several ports still have not conducted professional assessments and considerations of ship feasibility so that unexpected damage and accidents are often experienced by ships in sailing. Whereas the parties involved in transporting goods and people both in the people's shipping, between islands and ferry crossings, each party is responsible based on their respective roles and functions. The captain and ship owner as the direct perpetrators of "crime" (actus reus), while the supervisor in this case the porter and the regional transportation service are indirectly responsible. And if proven guilty, then article 302 and or 303 Laws 17 of 2008 concerning the shipping of Jo article 359 of the Criminal Code threatens to impose a sentence of 10 years and a fine of IDR. 1.5 billion.
\end{abstract}

Keyword: responsibility; sailor ship; citizen sailing

Abstrak: Angkutan laut yang mempunyai karakteristik pengangkutan secara nasional dan menjangkau seluruh wilayah melalui perairan perlu dikembangkan potensi dan ditingkatkan peranan sebagai penghubung antar wilayah, karena digunakan sebagai sarana untuk menunjang, mendorong, dan menggerakkan pembangunan nasional dalam upaya meningkatkan upaya kesejahteraan rakyat. Namun hingga saat ini otoritas perhubungan laut belum maksimal dalam menjalankan kewenangannya dalam memeriksa kelaik-lautan kapal. Dalam Prinsip dasar keselamatan pelayaran menyatakan bahwa kapal yang hendak berlayar harus berada dalam kondisi sea worthness atau laik-laut. Artinya, kapal harus mampu menghadapi berbagai cara termasuk kejadian ombak besar dan badai dalam 
pelayaran.

Pihak penyelenggara pelayaran di beberapa pelabuhan masih belum melakukan penilaian dan pertimbangan secara profesional terhadap kelaikan kapal sehingga kerusakan secara tak terduga dan atau kecelakaan sering dialami kapal pada saat berlayar. Bahwa pihak-pihak yang terkait dalam pengangkutan barang dan orang baik itu dalam pelayaran rakyat, antar pulau maupun penyeberangan feri, masingmasing pihak bertanggung jawab berdasarkan peran dan fungsi masing-masing. Pihak pengangkut nakhoda dan pemilik kapal sebagai pelaku langsung "kejahatan" (actus reus), sedangkan pihak pengawas dalam hal ini syahbandar maupun dinas perhubungan daerah bertanggung jawab tidak langsung. Dan apabila terbukti melakukan kesalahan maka dapat dikenakah pasal 302 dan atau 303 Undangundang No. 17 tahun 2008 Tentang pelayaran Jo pasal 359 KUHP ancaman hukumannya 10 tahun penjara dan denda sebesar Rp. 1.5 Miliar.

Kata kunci: tanggung jawab; pelayaran; pelayaran rakyat

\section{PENDAHULUAN}

Dalam Undang-Undang Nomor 17 Tahun 2008 tentang Pelayaran Pasal 1 Angka 1, diatur yang dimaksud dengan pelayaran adalah satu kesatuan sistem yang terdiri atas angkutan di perairan, kepelabuhanan, keselamatan dan keamanan, serta perlindungan lingkungan maritim..$^{1}$

Angkutan laut yang mempunyai karakteristik pengangkutan secara nasional dan menjangkau seluruh wilayah melalui perairan perlu dikembangkan potensi dan ditingkatkan peranan sebagai penghubung antar wilayah, karena digunakan sebagai sarana untuk menunjang, mendorong, dan menggerakkan pembangunan nasional dalam upaya meningkatkan upaya kesejahteraan rakyat.

Berdasarkan hal tersebut di atas, juga diatur dalam Undang-Undang Nomor 17 Tahun 2008 tentang Pelayaran mengenai Angkutan Laut Pelayaran Rakyat Pasal 1 Angka 5, bahwa Angkutan Laut Pelayaran Rakyat adalah usaha rakyat yang bersifat tradisional dan mempunyai karakteristik tersendiri untuk melaksanakan angkutan di perairan dengan menggunakan kapal layar, kapal layar bermotor, dan atau kapal motor sederhana berbendera Indonesia dengan ukuran tertentu.

Di Provinsi Sulawesi Tenggara, pelayaran merupakan bagian dari urat nadi dan jalur utama untuk angkutan daerah pedalaman dan kepulauan. Dalam menjalankan usahanya dibidang angkutan laut pelayaran rakyat baik angkutan berupa orang maka

1 Undang-Undang Nomor 17 Tahun 2008 tentang Pelayaran 
perlu diperhatikan oleh pengusaha kapal dan instansi terkait yang mempunyai kewenangan dalam penyelenggaraan pelayaran untuk memberikan jaminan keselamatan bagi penumpang.

Namun hingga saat ini otoritas perhubungan laut belum maksimal dalam menjalankan kewenangannya dalam memeriksa kelaik-lautan kapal. Pihak penyelenggara pelayaran di beberapa pelabuhan masih belum melakukan penilaian dan pertimbangan secara profesional terhadap kelaikan kapal sehingga accidental damage atau kerusakan secara tak terduga dan atau kecelakaan sering dialami kapal pada saat berlayar. Lebih lanjut dikatakan bahwa selama ini pihak penyelenggara pelayaran tidak cukup berani melakukan detention order atau perintah penahanan terhadap kapal yang tidak laik, dan pemeriksaan yang dilakukan lebih terkesan formalitas, semu bahkan tampak basa-basi.

Sebuah kapal bermuatan kontainer, KM. Pemudi tenggelam di perairan Banda. Dua kru kapal dinyatakan selamat, namun 19 awak kapal lainnya belum diketahui keberadaannya. Kedua ABK yang selamat itu ditemukan terapung, dengan menggunakan alat penolong bersama lima kontainer. "Kapal itu berangkat dari Surabaya tujuan Nabire Papua. Kapal itu mengangkut kontainer," kata Basrano, Kepala Seksi Operasi Kantor Search and Rescue Kendari. ${ }^{2}$

Kapal penumpang KM Sinar bangun tenggelam di kawasan perairan danau Toba di kabupaten Simalungun, Sumatera Utara. Yang menyisakan tanda Tanya soal jaminan keselamatan dalam angkutan penyeberangan yang dikarenakan minimnya pengawasan yang dilakukan oleh pihak yang bertanggung jawab. Dimana jumlah korban penumpang yang simpang siur. Dari data yang didapatkan 3 orang meninggal dunia, sekitar 184 orang hilang dan selamat 21 orang. Pihak kepolisian telah menetapkan 4 orang tersangka yang harus bertanggung jawab. Sebab, selain menetapkan nakhoda dan pemilik kapal sebagai pelaku langsung "kejahatan" (actus reus) kepolisian juga menetapkan 3 orang penjabat Dishub yang secara sistematis membiarkan KM Sinar Bangun kelebihan kapasitas. Dimana tersangka dijerat dengan pasal 302 dan atau 303 Undang-undang No. 17 tahun 2008 Tentang pelayaran Jo pasal 359 KUHP ancaman hukumannya 10 tahun penjara dan denda

2 Kiki Andi Pati, Kapal Bermuatan Kontainer Tenggelam di Laut Banda, 19 ABK Hilang, Kompas.com, https://regional.kompas.com/read/2013/07/07/1800025/Kapal.Bermuatan.Kontainer.Tenggelam.di.L aut.Banda.19.ABK.Hilang, diakses pada tanggal 8 Juli 2018. 
sebesar Rp. 1.5 Miliar. Dari hasil analisa gros tonnya 17. Harusnya hanya bisa menampung 40 orang penumpang. Serta tidak dilengkapi alat keselamatan penumpang. ${ }^{3}$

Belum diangkatnya korban KM Sinar bangun yang tenggelam di kawasan perairan danau Toba di kabupaten Simalungun, Sumatera Utara. Kembali kita dikejutkan berita tenggelamnya kapal feri di perairan selat Selayar Provinsi Sulawesi Selatan. Pada hari Rabu 4 Juli 2018. Kapal Motor Penumpang (KMP) Lestari Maju mengalami insiden tragis yang berakibat adanya korban jiwa, Selasa (3/7/2018) siang. Kapal yang mengangkut ratusan penumpang ini karam. Korban tewas akibat tenggelamnya KM Lestari Maju di antara Pulau Pasi dan Pelabuhan Pamatata, Kabupaten Kepulauan Selayar, Sulawesi Selatan, Selasa (3/7/2018) siang, bertambah. Korban meninggal 39 orang, yang selamat 153 orang. ${ }^{4}$

Dalam pelayaran antar pulau di provinsi Sulawesi Tenggara khususnya pelayaran dengan rute Kendari-Wawonii, Kendari-Laonti, Amolenggu Konsel-Lasiwa Kab Muna, Kendari-Wanci dan beberapa kapal dengan rute Kendari-Menui (Sulawesi Tengah) dengan menggunakan kapal motor dan kapal feri masih terdapat penyimpangan-penyimpangan terhadap regulasi kelaik lautan kapal misalnya saja di antaranya:

a. Kapal motor kurang dilengkapi dengan alat-alat penyelamat bagi penumpang.

b. Penumpang yang dimuat pada kapal motor selalu melebihi kapasitas muatan kapal. Hal ini sesuai dengan ketentuan yang diatur dalam Peraturan Pemerintah Nomor 17 Tahun 1988 tentang Penyelenggaraan dan Pengusahaan Angkutan Laut Pasal 14 Huruf (b), bahwa untuk menyelenggarakan Usaha Pelayaran Rakyat wajib dipenuhi persyaratan dengan memiliki unit perahu layar atau kapal layar motor dengan ukuran sampai dengan $850 \mathrm{M}^{3}$ isi kotor atau kapal motor dengan ukuran sampai dengan $100 \mathrm{M}^{3}$.

c. Sering terjadi over kapasitas sehingga terjadi penumpukan barang.

d. Konstruksi kapal telah mengalami kondisi kapal yang tidak memenuhi standar dimana kapal sebelum berlayar harusnya telah memenuhi standar kelaiklautan kapal, sehingga tidak memungkinkan untuk melakukan suatu pelayaran.

3 Sandro Gatra. KM Sinar Bangun Tenggelam di Danau Toba, 189 Orang Dilaporkan Hilang, Kompas.com, https://regional.kompas.com/read/2018/06/20/09261281/km-sinar-bangun-tenggelam-di-danautoba-189-orang-dilaporkan-hilang, diakses pada tanggal 7 Juli 2018.

4 Fitriadi, Kronologi Lengkap Tenggelamnya Kapal Feri di Selayar, 25 Orang Tewas, 30 M Uang Gaji ke-13 Lenyap, Bangkapos.com, $\quad$ http://bangka.tribunnews.com/2018/07/04/kronologi-lengkaptenggelamnya-kapal-feri-di-selayar-25-orang-tewas-30-m-uang-gaji-ke-13-lenyap diakses pada tanggal 7 Juli 2018. 
e. Konstruksi kapal yang tidak seimbang tinggi 4 meter dibuat 3 lantai.

Prinsip dasar keselamatan pelayaran menyatakan bahwa kapal yang hendak berlayar harus berada dalam kondisi sea worthness atau laik-laut. Artinya, kapal harus mampu menghadapi berbagai cara termasuk kejadian ombak besar dan badai dalam pelayaran. Kelayakan kapal juga mensyaratkan konstruksi kapal dan kondisi mesin harus dalam keadaan baik. Sehingga jika suatu saat terjadi kecelakaan laut maka pihak penyelenggara pelayaran dapat melepas tanggung jawab dengan dalih bahwa kapal tersebut sudah laik laut.

Namun hingga saat ini otoritas perhubungan laut masih gagal menjalankan kewenangannya dalam memeriksa kelaik-lautan kapal. Pihak penyelenggara pelayaran di beberapa pelabuhan masih belum melakukan penilaian dan pertimbangan secara profesional terhadap kelaikan kapal sehingga kerusakan secara tak terduga dan atau kecelakaan sering dialami kapal pada saat berlayar.

\section{ANALISIS DAN PEMBAHASAN}

\section{Keselamatan Transportasi}

Salah satu tanggung jawab Negara adalah memberikan kemudahan akses kepada setiap warga Negara untuk melakukan aktivitas antar atau dari satu wilayah ke wilayah lainnya di Negara Republik Indonesia. Apalagi Negara Indonesia adalah Negara maritim yang terdiri dari puluhan ribu pulau yang satu kesatuan yang kita sebut sebagai Nusantara. Untuk menghubungkan wilayah satu ke wilayah lainnya maka dibutuhkan transportasi yang memadai, agar warga Negara Indonesia mendapat jaminan keselamatan. Yang merupakan hak asasi manusia., dalam rangka mendukung peri kehidupannya. Maka perlunya Sistem transportasi yang aman dan lancar agar pergerakan manusia dan barang. Mendapat keselamatan (safety) baik orang maupun barangnya. Siapa pun yang melakukan perjalanan wajib mendapatkan jaminan keselamatan serta kenyamanan untuk barangbarang yang diangkut harus tetap dalam keadaan utuh dan tidak berkurang kualitasnya ketika sampai di tujuan. Ini sesuai dengan definisi pengangkutan yang bertujuan mengantar orang atau barang dari tempat satu ke tempat lainya dengan selamat.

Suatu layanan transportasi yang dilengkapi dengan jaminan keselamatan akan memberikan rasa kepastian dan ketenangan bagi pelaku perjalanan, sehingga kegiatan sosial ekonomi masyarakat dapat terlindungi ketika melakukan perjalanan. Tidak adanya jaminan rasa aman, selalu merasa waswas baik sebagian perjalanan, maupun perjalanan 
sambungannya, ataupun seluruh proses perjalanannya. Jika aspek keselamatan transportasi terjamin, dan hak masyarakat pengguna terlindungi, niscaya tidak akan muncul biaya-biaya tidak terduga yang merugikan masyarakat pengguna. Pada prinsipnya, masalah ketertiban dan keselamatan adalah tanggung jawab bersama antara pemerintah, pihak swasta, pelaku dan pengguna jasa transportasi, serta seluruh masyarakat.

\section{Jaminan Keselamatan Dalam Pengangkutan Pelayaran Rakyat}

Menurut Sution Usman Adji mengenai pengusaha kapal terdapat empat orang yang memegang peranan penting, mereka itu adalah :
a. Reder (Pengusaha Kapal)
b. Nahkoda
c. Pengangkut
d. Pemilik

Pengusaha kapal (reder) menurut Pasal 320 KUHD menentukan bahwa pengusaha adalah dia, yang memakai sebuah kapal di laut dan menjalankannya sendiri atau seluruh menjalankan oleh seorang nakhoda yang bekerja padanya. Sungguhpun biasanya seorang pengusaha kapal biasanya adalah pemilik kapal. ${ }^{5}$

Menurut Usman Adji, tanggung jawab pengusaha kapal (Reder), membagi :

a. Pasal 321 KUHD sebagai seorang reder ia menguasai kapal secara kenyataan (feite) oleh karena itu pada hakikatnya ialah yang bertanggung jawab atas segala kejadian di kapal yang bersangkutan.

b. Pasal 321 KUHD ayat (1) menentukan bahwa pengusaha kapal terkait oleh segala perbuatan hukum yang dilakukan oleh mereka yang bekerja tetap atau sementara pada kapal-kapalnya, di jabatan mereka dalam lingkungan kekuasaan mereka. Kalau ayat ini dikupas maka yang mengikat reder adalah:

1) Perbuatan hukum oleh mereka yang bekerja dikapal

2) Dalam pekerjaan tetap atau sementara

3) Ayat (2) menegaskan: reder bertanggung jawab untuk segala kerugian yang diterbitkan pada pihak yang melanggar hukum

5 Sution Usman Adji dkk., Hukum Pengangkutan di Indonesia, Jakarta: Rineka Cipta, 1991, hlm. 290. 
4) Pasal 536 menentukan reder dari kapal yang telah melakukan kesalahan harus bertanggung jawab. Dan juga pasal 568 KUHD dan 537 ayat (3) KUHD. 6

Dalam Pasal 522 ayat (1) KUHD yang menyatakan bahwa perjanjian untuk mengangkut mewajibkan pengangkut untuk menjaga keamanan penumpang dari saat naik sampai saat turun dari kapal. Ayat (2), menjelaskan bahwa pengangkut wajib mengganti kerugian, yang disebabkan oleh cedera yang menimpa menumpang berkenaan dengan pengangkutan, kecuali ia dapat membuktikan, bahwa cedera itu akibat dari suatu peristiwa yang layaknya tidak dapat dicegah atau dihindari, atau akibat kesalahan dari penumpang sendiri. Ayat (3), menjelaskan bahwa bila cedera itu mengakibatkan kematian, maka pengangkut wajib mengganti kerugian yang karenanya diderita oleh suami atau istri yang ditinggalkan, anak-anak dan orang tua penumpang itu.

Dalam Pasal 537 ayat (1), menjelaskan bahwa bila tubrukan kapal adalah akibat kedua belah pihak, tanggung jawab kedua pengusaha kapal seimbang dengan kesalahankesalahan yang dilakukan oleh kedua belah pihak. Ayat (2), menjelaskan bahwa perbandingan ini ditetapkan oleh hakim tanpa ditunjukkan oleh orang yang menuntut ganti rugi. Bila hal itu tidak dapat ditetapkan, maka para pengusaha kapal itu bertanggung jawab untuk segala bagian-bagian yang sama. Ayat (3), menjelaskan bahwa bila ada seorang yang meninggal atau terluka, maka masing-masing pengusaha kapal bertanggung jawab terhadap pihak ketiga untuk seluruh kerugian yang diderita karenanya. Pengusaha kapal yang karena itu telah membayar lebih dari pada bagian yang dihitung dengan cara yang disebut dalam alinea pertama dengan mempunyai tagihan terhadap sesama debitur bersama.

Dalam Undang-Undang Nomor 17 Tahun 2008 Pasal 40 ayat (1), bahwa perusahaan angkutan di perairan bertanggung jawab terhadap keselamatan dan keamanan penumpang dan/atau barang yang diangkutnya. Kemudian dipertegas pada pasal 41 ayat (1), (2), dan (3) Undang-Undang Nomor 17 Tahun 2008 tentang Pelayaran, bahwa; Ayat (1) Tanggung jawab sebagaimana dimaksud dalam pasal 40 dapat ditimbulkan sebagai akibat pengoperasian kapal, berupa:

a. Kematian atau lukanya penumpang yang diangkut

b. Musnah, hilang, atau rusaknya barang yang diangkut

$6 \quad$ Ibid., hlm. 291. 
c. Keterlambatan angkutan penumpang dan/ atau barang yang diangkut, atau

d. Kerugian pihak ketiga

Ayat (2) jika pihak membuktikan bahwa kerugian sebagaimana dimaksud pada ayat (1) huruf b, huruf c, dan huruf d bukan disebabkan oleh kesalahannya, perusahaan angkut di perairan dapat dibebaskan sebagian atau seluruh tanggung jawabnya. Ayat (3), perusahaan angkutan di perairan wajib, mengasuransikan tanggung jawabnya sebagaimana dimaksud pada ayat (1) dan melaksanakan asuransi perlindungan dasar penumpang umum sesuai dengan ketentuan peraturan perundang-undangan. ${ }^{7}$

\section{Peran Pengawas Pengangkutan Laut dalam mewujudkan keselamatan}

Dalam sistem keselamatan pengangkutan laut, peran pengawas pengangkutan laut sangat dibutuhkan. Dalam hukum pelayaran Indonesia yang mengatur mengenai keamanan dan keselamatan penumpang diamanatkan pada Syahbandar. Yang dalam struktur organisasi Kementerian Perhubungan berada dalam Direktorat Jenderal Perhubungan. Yang terdiri kantor kesyahbandaraan utama dan kesyahbandraan dan otoritas pelabuhan. Yang masing-masing kantor mempunyai tugas yang berbeda. Dalam makalah ini kami membahas kantor Kesyahbandaraan dan Otoritas Pelabuhan. Sebab kita hanya membahas tentang pelayaran rakyat, kapal motor serta kapal penyeberangan Fery.

Menurut Pasal 3 Peraturan Menteri Perhubungan Nomor PM 36 Tahun 2012 tentang Organisasi Tata kerja Kantor syahbandar dan Otoritas Pelabuhan fungsi dari kantor Kesyahbandaraan dan Otoritas Pelabuhan adalah :

1. Pelaksanaan pengawasan dan pemenuhan kelaiklautan kapal, sertifikasi kapal, pencegahan pencemaran dari kapal dan penetapan status hukum kapal.

2. Pelaksanaan pemeriksaan manajemen keselamatan kapal.

3. Pelaksanaan pengawasan keselamatan dan keamanan pelayaran terkait dengan kegiatan bongkar muat barang berbahaya, barang khusus, limbah berbahaya dan beracun (B3), pengisian bahan bakar, ketertiban embarkasi dan debarkasi penumpang, pembangunan fasilitas pelabuhan, pengerukan dan reklamasi, laik layar dan kepelautan, tertib lalulintas kapal di perairan pelabuhan dan alur pelayaran, pemanduan dan penundaan kapal, serta penerbitan surat persetujuan berlayar.

7 Undang-Undang Nomor 17 Tahun 2008 tentang Pelayaran. 
4. Pelaksanaan pemeriksaan kecelakaan kapal, pencegahan dan pemadaman kebakaran di perairan pelabuhan, penanganan musibah di laut, pelaksanaan perlindungan lingkungan maritim dan penegakkan hukum di bidang keselamatan dan keamanan pelayaran.

5. Pelaksanaan koordinasi kegiatan pemerintah di pelabuhan yang terkait dengan pelaksanaan pengawasan dan penegakkan hukum di bidang keselamatan dan keamanan pelayaran. ${ }^{8}$

Masih diatur hal teknis lainnya yang di atur dari poin 6 sampai 11 yang berkaitan tentang penyusunan induk kepelabuhanan, pengawasan penggunaan lahan daratan, pelaksanaan lalulintas kapal, evaluasi setandar pelayanan kerja dan pelaksanaan keuangan pelabuhan. pelaksanaan pengawasan dan pemenuhan kelaiklautan kapal, sertifikasi kapal, pencegahan pencemaran dari kapal dan penetapan status hukum kapal.

Dari uraian tugas berdasarkan pasal 3 PM No. 36 Tahun 2012 di atas makan syahbandar sangat berperan dalam melaksanakan pengawasan atas keselamatan kapal terhadap penumpang dan barang. Dalam melaksanakan pengawasan manajemen keselamatan kapal. Serta Pelaksanaan pengawasan keselamatan dan keamanan pelayaran terkai dengan kegiatan bongkar muat barang berbahaya, barang khusus, limbah berbahaya dan beracun (B3), pengisian bahan bakar, ketertiban embarkasi dan debarkasi penumpang, pembangunan fasilitas pelabuhan, pengerukan dan reklamasi, laik layar dan kepelautan, tertib lalulintas kapal di perairan pelabuhan dan alur pelayaran, pemanduan dan penundaan kapal, serta penerbitan surat persetujuan berlayar.

Sehingga apabila terjadi kecelakaan kapal maka syahbandar melakukan koordinasi dengan pihak-pihak yang terkait di pelabuhan yang terkait dengan pelaksanaan pengawasan dan penegakkan hukum di bidang keselamatan dan keamanan pelayaran.

Maka diharapkan pihak syahbandar dalam mengeluarkan surat persetujuan berlayar haruslah sangat hati-hati untuk terlebih dahulu melakukan tahapan-tahapan prosedur pemeriksaan agar kapal yang berlayar benar-benar sudah dinyatakan laiklaut mulai dari manajemen kapal, keselamatan kapal, alat-alat keselamatan penumpang, mesin, kondisi kapal, jumlah barang dan penumpang harus sesuai antara gros ton dengan kapasitas angkut barang dan orang. Sehingga ketiga mengeluarkan surat persetujuan berlayar sudah safety.

8 Peraturan Menteri Perhubungan Nomor PM 36 Tahun 2012 tentang Organisasi Tata Kerja Kantor Syahbandar dan Otoritas Pelabuhan 


\section{KESIMPULAN}

Berdasarkan pembahasan di atas kami menarik kesimpulan bahwa pihak-pihak yang terkait dalam pengangkutan barang dan orang baik itu dalam pelayaran rakyat, antar pulau maupun penyeberangan feri, masing-masing pihak bertanggung jawab berdasarkan peran dan fungsi masing-masing. Pihak pengangkut nakhoda dan pemilik kapal sebagai pelaku langsung "kejahatan" (actus reus), sedangkan pihak pengawas dalam hal ini syahbandar maupun dinas perhubungan daerah bertanggung jawab tidak langsung.

Apabila terbukti melakukan kesalahan maka dapat dikenakah pasal 302 dan atau 303 Undang-undang No. 17 tahun 2008 Tentang pelayaran Jo pasal 359 KUHP ancaman hukumannya 10 tahun penjara dan denda sebesar Rp. 1.5 Miliar

Pihak-pihak yang terkait dalam pengangkutan laut harus berhati-hati dalam menjalankan usaha pengangkutan tidak hanya mengejar keuntungan tapi mengabaikan jawab Manusia, harus menyediakan alat keselamatan penumpang. Begitu juga pihak pengawas pengangkutan laut dalam hal ini pihak syahbandar untuk tidak mudah mengeluarkan surat kelayakan berlayar. Agar peristiwa kecelakaan kapal laut di Negara Indonesia bisa dihindari.

\section{Daftar Pustaka}

\section{Buku}

Usman Adji, Sution, dkk. Hukum Pengangkutan di Indonesia, Jakarta: Rineka Cipta, 1991

\section{Peraturan Perundang-Undangan}

Kitab Undang-Undang Hukum Pidana

Kitab Undang-Undang Hukum Dagang

Undang-Undang Nomor 17 Tahun 2008 tentang Pelayaran

Peraturan Menteri Perhubungan Nomor PM 36 Tahun 2012 tentang Organisasi Tata Kerja Kantor Syahbandar dan Otoritas Pelabuhan

\section{Situs Internet}

Fitriadi, Kronologi Lengkap Tenggelamnya Kapal Feri di Selayar, 25 Orang Tewas, 30 M Uang Gaji ke-13 Lenyap, Bangkapos.com, http://bangka.tribunnews.com/ 
2018/07/04/kronologi-lengkap-tenggelamnya-kapal-feri-di-selayar-25-orangtewas-30-m-uang-gaji-ke-13-lenyap, diakses pada tanggal 7 Juli 2018.

Gatra, Sandro. KM Sinar Bangun Tenggelam di Danau Toba, 189 Orang Dilaporkan Hilang, Kompas.com, https://regional.kompas.com/read/2018/06/20/09261281/kmsinar-bangun-tenggelam-di-danau-toba-189-orang-dilaporkan-hilang, diakses pada tanggal 7 Juli 2018.

Pati, Kiki Andi, Kapal Bermuatan Kontainer Tenggelam di Laut Banda, 19 ABK Hilang, Kompas.com, https://regional.kompas.com/read/2013/07/07/1800025/Kapal. Bermuatan.Kontainer.Tenggelam.di.Laut.Banda.19.ABK.Hilang, diakses pada tanggal 8 Juli 2018. 